\title{
Characteristic changes in aerosol and meteorological parameters associated with dust event of 9 March 2013
}

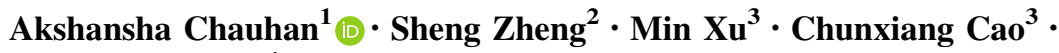 \\ Ramesh P. Singh ${ }^{4}$
}

Received: 6 September 2016/Accepted: 28 September 2016/Published online: 15 October 2016

(c) Springer International Publishing Switzerland 2016

\begin{abstract}
Dust storms are very common in China during spring (March-May) season. On 8-9 March 2013, an intense dust storm occurred, which affected north-eastern parts of China including capital city Beijing. Satellite data are very important in tracking dust events; satellite and ground observations provide very important information about the transport of dust, their optical, atmospheric and meteorological parameters. In this paper, we present detailed characteristic of aerosol and meteorological parameters associated with dust storm. Using Atmospheric Infrared Sounder (AIRS) data, meteorological parameters and $\mathrm{CO}$ volume mixing ratio at different pressure levels have been studied. A pronounced change in aerosol and meteorological parameters, $\mathrm{CO}$ volume mixing ratio (COVMR) were observed on ground and also with the altitudes over Beijing. The recent pollution index (AQI) being used by China from beginning of 2013 shows a decrease in value with the dust storm, which is not a true representation of dust storm when the air quality is poor. In contrast, AQI was very high during February and March
\end{abstract}

Akshansha Chauhan

akshansha1886@gmail.com

1 Vidya College of Engineering, Baghpat Road, Meerut 250002, India

2 Department of Land Management, Zhejiang University, Yuhangtang Road, Hangzhou 310058, People's Republic of China

3 State Key Laboratory of Remote Sensing Science, Jointly Sponsored by the Institute of Remote Sensing and Digital Earth of Chinese Academy of Sciences and Beijing Normal University, Beijing 100101, People's Republic of China

4 School of Life and Environmental Sciences, Schmid College of Science and Technology, Chapman University, One University Drive, Orange, CA 92866, USA associated with the dense fog and intense haze in Beijing especially during the last week of March 2013.

Keywords MODIS · AIRS · AQI · Dust · Aerosols

\section{Introduction}

China suffers with intense desertification, which has direct impact on the environment, society and economy (Wang et al. 2004). Northern China is covered by deserts, approximately 1.653 million $\mathrm{km}^{2}$, and faces frequent dust storms (Zheng et al. 2014). Some of the early records of dust storm activities in northern China are referred as "yellow wind" or "black wind" (Zhang et al. 2005, 2012), as well as "dust rain" or "dust fog" (Qian et al. 2002). The record of dust storm can be traced back up to about 3150 years ago (Wang et al. 2004).

Beijing, capital city is located in a basin surrounded by the Taihang Mountain in the south-west and Yan Mountain in the north-west. During spring and early summer seasons, every year city is affected by dust storms, these dusts storms are transported from arid areas of Northern China and Mongolia (Zhang et al. 2005; Wang et al. 2006; Cao et al. 2014; Zheng et al. 2014). Beijing city is having serious air pollution problem (Chen et al. 2009) due to various sources such as, coal based power plants, industries, transportation, dust storms, biomass burning and road dusts. The increasing air pollution have serious health threat to 21 million people living in Beijing.

Dust storms are considered as a major natural disaster that has short and long term impacts on public health (Prospero 1999; Tong et al. 2012; Singh 2014; Cao et al. 2014; Zheng et al. 2014). Continuous dust storms in the long term can also affect the Earth's climate, snow and 
glaciers (Prasad and Singh 2007a, b; Painter et al. 2012; Zhao et al. 2012; Gautam et al. 2013; Singh 2014). Dust storms are common in China and occur annually during spring season (March-May) (Cao et al. 2014). During dust events, Beijing is influenced by dust highly affecting air quality and visibility (Liu et al. 1981).

Mineral dust aerosols can be subjected to long range transport depending upon the intensity of dust storms which is controlled by the wind flow and convective activity. Dust outflow from China has been frequently observed in Korea and Japan, and across the Pacific (Uno et al. 2011). The long range dust transport influences meteorological parameters, visibility, and hydrological cycle (Bhattacharjee et al. 2007; Gautam et al. 2011). Deposition of desert dust has also been observed in the mountain snowpack and glaciers (Prasad and Singh 2007b; Painter et al. 2012; Gautam et al. 2013), that may accelerate the melting of snow and ice. Dust transported over the ocean/sea influences the oceanic ecosystem inducing enhancement of chlorophyll concentrations especially in the coastal ocean (Kayetha et al. 2007, Singh et al. 2008). Advection of dust from the boundary layer into the free troposphere also influences tropospheric temperatures, and the distribution of water vapor and carbon monoxide in the atmosphere (Bhattacharjee et al. 2007; Prasad and Singh 2007a; Gautam et al. 2011; Singh 2014). Yet, the interactions of dust with the hydrological and biogeochemical cycles are not fully understood, mainly due to lack of information and in-depth characteristics of dust aerosols.

Du et al. (2008) have analyzed aerosol observational data for three years period (2005-2007) from the Chinese Sun Haze eter Network (CSHNET) to study the optical properties of aerosols for dusty and non-dusty days during spring season. The mean aerosol optical depth (AOD) during spring season enhanced by $33 \%$ due to dust events compared to non-dusty days based on three years observations (Du et al. 2008). In addition, the Ångström exponent $(\alpha)$ decreased by $24 \%$ due to dust events compared to non-dusty days. Apart from dust influence, pronounced changes in the aerosol parameters (aerosol optical depth, AOD and Ångström exponent, $\alpha$ ) were observed with the anthropogenic emissions (Du et al. 2008). Xin et al. (2010) have analyzed aerosol data from eight ground observation sites as a part of the CSHNET to characterize the optical properties of aerosol particles during strong dust event 16-21 April 2005. Pronounced increase up to $86 \%$ in AOD is observed during dust storm in Beijing. The air pollution index (API) (Zheng et al. 2014) in Beijing also shows a similar enhancement during the dust storm, while the Ångström exponent $(\alpha)$ reduced up to $21 \%$ in Beijing which is obviously due to dominance of coarse mode dust particles. Furthermore, the dust module in a regional climate model (RegCM3) simulated the dust storm occurrence and track accurately and RegCM3 was able to simulate the trends in AOD (Xin et al. 2010). Huang et al. (2010) analyzed the impact of dust aerosols on the semiarid climate of Northwest China by comparing aerosol and cloud properties derived over the China semi-arid region (CSR) and the United States semi-arid region (USR) using several years of surface and A-Train satellite observations during active dust event seasons. These regions have similar climatic conditions, but aerosol concentrations are greater over the CSR. During dust event periods, liquid water cloud particle size, optical depth and liquid water path are smaller compared to dust-free conditions (Huang et al. 2010). Yu et al. (2011) carried out a comparative study on the aerosol optical properties of two kinds of severe pollution events (dust and haze-fog) that occurred during 2001-2007. The AOD shows a distinct variation under different weather conditions, with an average AOD of 1.70 for dusty days and 1.26 for haze-fog days. The Ångström exponent $(\alpha)$ values for dusty days were lower compared to those for dense haze and fog days.

The large dust storm of 9 March 2013 observed over Beijing and surrounding areas originated from the Mongolian border and transported to China northeastern plains and further transported to southwest of Beijing. The air quality in Beijing deteriorated as this sandstorm spread and thick smog added to the problem. The smog and dust also crossed the Bohai Gulf to the Korean Peninsula and further to Japan. The city of Tokyo was also affected by the dust which disturb the visibility and color of the sky as dry dust particles whirled through the air. The daily real time data of trace gases and air quality parameters $\left(\mathrm{NO}_{2}, \mathrm{CO}, \mathrm{SO}_{2}, \mathrm{O}_{3}, \mathrm{PM}_{2.5}\right.$, and $\left.\mathrm{PM}_{10}\right)$ (available through Beijing Municipal Environmental Monitoring Centre, BMEMC), show poor air quality of Beijing which is associated with the dust storm (9 March 2013). At 9:00 am on 9 March, dust reached the Beijing area from northwestern region; the hourly concentration of $\mathrm{PM}_{10}$ increased rapidly, from about $500 \mu \mathrm{g} / \mathrm{m}^{3}$ in monitoring sites of Baihuashan, Mentougou, and Dingling to $1000 \mu \mathrm{g} / \mathrm{m}^{3}$ in Guanyuan monitoring site, at around noon time. The observed wind speed at Beijing airport was $30 \mathrm{~m} / \mathrm{s}$ (http://epaper.dfda ily.com/dfzb/html/2013-03/10/content_744113.htm).

In this paper, we have carried out detailed ground and satellite observed data to study the changes in several aerosol optical and meteorological parameters [AOD, Ångström exponent, fine particles, total ozone column, air quality index (AQI), water column (WC), relative humidity (RH)] associated with the dust event which was observed over Beijing, China on 9 March 2013. AIRS data provide information at different altitudes in terms of pressure levels, using AIRS data first time we have studied changes in meteorological and atmospheric parameters at different pressure levels associated with the dust event of 9 March 2013 over Beijing. 


\section{Ground station description, satellite data and HYSPLIT model}

We have used satellite, air quality and ground AERONET data. The AERONET (Aerosol Robotic Networks) Program (http://aeronet.gsfc.nasa.gov/) aims to study aerosols by ground sun photometer mainly to validate aerosol optical properties retrieved from satellites (Holben et al. 1998). The Sunphotometer deployed under the AERONET is calibrated time to time by NASA Aeronet team. AERONET data is extensively used to study aerosol characteristics (physical and chemical). We have used AERONET data (version 2) from Beijing (N-39.98, E-116.38). We have studied total column aerosols properties such as AOD $\left(\tau_{\mathrm{a} 500 \mathrm{~nm}}\right)$, Angström exponent $\left(\alpha_{470-870 \mathrm{~nm}}\right)$, water column, volume particle size distribution $(\mathrm{dV} / \mathrm{dLnR})$ and reflective index over Beijing Station, China on dusty day which was observed in Beijing on 9 March 2013. The detailed methodology of retrieval of aerosol parameters from AERONET stations are discussed in detail by Dubovik and King (2000) and Dubovik et al. (2000). We have used MODIS satellite data to analyze aerosol optical depth (AOD) and Angström exponent $(\alpha)$ and also MODIS AQUA (around $1.30 \mathrm{pm}$ ) and TERRA (around $10.30 \mathrm{am}$ ) images to find out the extent of dust.

NOAA HYSPLIT trajectory model (http://ready.arl. noaa.gov/HYSPLIT.php) is used to study the origin of air mass (dust) and its track at different altitudes. We have taken $120 \mathrm{~h}$ the long range transport of air mass reaching over Beijing at different altitudes. The back trajectories available after running NOAA HYSPILT model is overlain with the GOOGLE Earth and the image are analyzed. To compute the back trajectories the GDAs meteorological fields with spatial resolution of $1^{\circ}$ have been used. We have also used the AIRS Level-3 data (http://gdata1.sci.gsfc. nasa.gov/daac-bin/G3/gui.cgi?instance_id=AIRS_Level3 Daily) to study changes in meteorological parameters such as relative humidity $(\mathrm{RH})$, ozone volume mixing ratio $\left(\mathrm{O}_{3}\right.$ VMR), total ozone column (TOC), $\mathrm{CO}$ volume mixing ratio (COVMR), associated with dust event over Beijing city. We have considered both ascending and descending modes data, ascending mode when the satellite passes south to north, whereas the descending mode is when the satellite passes from north to south over the Earth's surface. In ascending mode the local pass time is around $1.30 \mathrm{pm}$ (day time) and in descending mode local pass time is around $1.30 \mathrm{am}$ (night time). Satellite data used in the present paper are downloaded through NASA Giovanni tool.

The air quality index (AQI) (Zheng et al. 2014) in Beijing are downloaded from BMEPB (Beijing Municipal Environmental Protection Bureau, http://www.bjepb.gov.cn). In order to inform the citizens about air quality and potential harmful conditions, BMEPB provides daily AQI data through its website since January 1, 2013. AQI simplifies the concentrations of several air pollutants for conventional monitor to single digit mode, and characterizes air pollution level and air quality status. Six air pollutants $\mathrm{SO}_{2}, \mathrm{NO}_{2}$, $\mathrm{PM}_{10}, \mathrm{CO}, \mathrm{O}_{3}$, and $\mathrm{PM}_{2.5}$ are used to compute AQI, high AQI refers to poor air quality (Zheng et al. 2014), and six levels of $\mathrm{AQI}$ are given below:

- 0-50 Good

- 51-100 Moderate

- 101-150 Unhealthy for sensitive groups

- 151-200 Unhealthy

- 201-300 Very unhealthy

- >300 Hazardous

\section{Results and discussion}

Figure 1a shows a strong dust storm over China and Mongolia (MODIS image of 9 March 2013, https://earth data.nasa.gov/labs/worldview/). The dust storm blankets the north eastern parts (Beijing and surrounding cities) of China during (March 08 and 09, 2013) and also the ocean region, the dust further spreads over to neighboring countries. The dust observed on 9 March was transported to southwest of Beijing, MODIS Terra image taken around 10.30 am clearly shows transport of dust over Hubei and up to Chengdu city further southwest.

We have considered average daily AQI data from all the 23 ground monitoring sites deployed in Beijing to have good coverage of AQI, daily average AQI, $\mathrm{PM}_{2.5}$ and $\mathrm{AOD}$ are shown for the period 1 February 2013-31 March 2013 in Fig. 1b. Prior to evening of 8 March 2013, Beijing repeatedly encountered fog and haze showing high values of AQI, PM ${ }_{2.5}$ and AOD. On 8 March 2013, the wind speed in Beijing was low, and fog and haze continued but high AQI (252) and AOD (0.468) were observed. At night on 8 March 2013, the wind was strong and dust storm hit Beijing. On 9 March 2013, the fog and haze was affected by dust so one can see strong aerosol mixing, Sudden drop in AQI (148) and AOD (0.287) on 9 March 2013 likely due to scattered rainfall, decrease in AQI and AOD was further observed on 10 March 2013, respectively to 66 (AQI) and 0.076 (AOD). Similar characteristics were observed of the dust storm of 28 February 2013 in Beijing. From 27 February 2013 due to fog and haze, both AQI and AOD (500 nm wavelength) were high prior to dust storm and AQI and AOD decreased after the dust storm showing good air quality and visibility on 1 March 2013. $\mathrm{PM}_{2.5}$ measured at the US Embassy in Beijing (Fig. 1b). In general, a correspondence in AQI, $\mathrm{PM}_{2.5}$ and $\mathrm{AOD}$ is clearly seen, 
Fig. 1 a NASA Worldview image of Dust event on 9 March, 2013 over Beijing, China (https://earthdata.nasa. gov/labs/worldview/). b Variations of daily averaged $\mathrm{PM}_{2.5}$, AQI and Aerosol Optical Depth (AOD) for Feb-March 2013
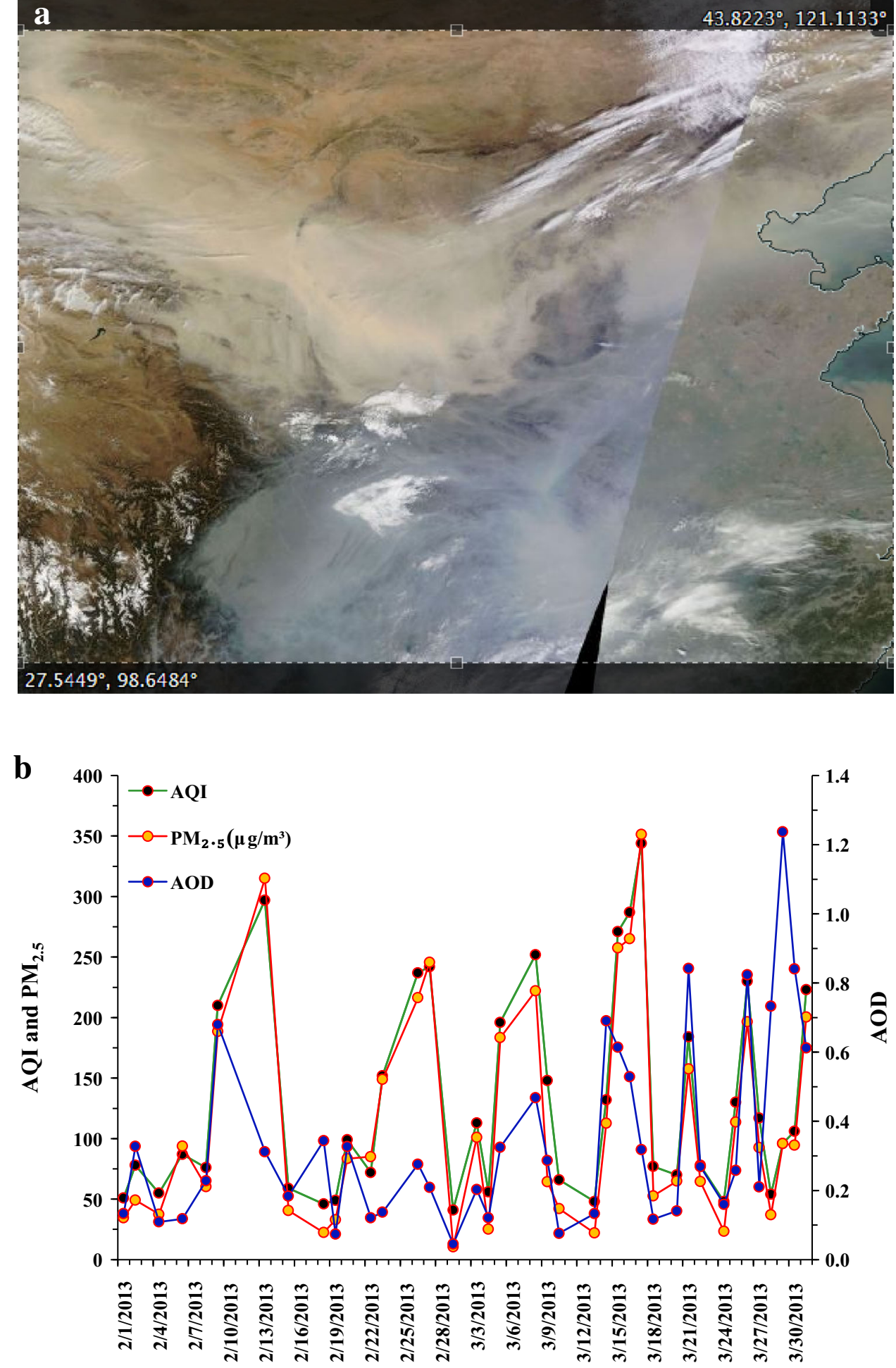

Date sometime correspondence is not seen which could be mainly due to spatial distribution of measurement sites of AQI, $\mathrm{PM}_{2.5}$ was only from US Embassy site. On 9 March, 2013 due to dust event, higher AOD, $\mathrm{PM}_{2.5}$ and AQI are observed. In the last week of March 2013 higher AOD,
$\mathrm{PM}_{2.5}$ and $\mathrm{AQI}$ are associated with the dense haze and fog. In contrast, AQI was very high during February and March associated with the dense fog and intense haze in Beijing. The air-mass trajectory using NOAA HYSPLIT trajectory model confirms the source of air mass from desert region 
reaching to Beijing (Fig. 2) and further transported to southwest direction over Hubei and Chengdu. The back trajectory shows source of air-mass from desert in the northern part of China and Mongolia. The back trajectories computed from NOAA HYSPILT are overlain on MODIS Terra image of 9 March 2013 and GOOGLE Earth.

Daily variations of AOD, Ångström exponent and water column (WC) retrieved from Beijing AERONET station (39.98N, 116.38E) are shown in Fig. 3a. The average AOD (1.03), Ångström exponent $(0.86)$ and $\mathrm{WC}(0.70 \mathrm{~cm})$ are for the month of March 2013 during 1-11 March 2013. On 6-8 March 2013 higher AOD (1.2) AE (0.7-1.0) are observed due to presence of smoke and biomass burning, however high AOD (1.13) with low Ångström exponent (AE) (0.15) was observed which is due to dust storm on 9 March 2013. Low AE values are the characteristics of coarse particles due to dust. Higher water column more than $0.6 \mathrm{~cm}$ is observed on the day of dust storm and scattered rainfall over Beijing was also reported. High water column on 8-9 and 11 March 2013 is due to the changes in cloud property as a result of dust and cloud interaction (Bhattacharjee et al. 2007). Scattered rainfall is common after the dust storm (Singh 2014, Kumar et al. 2015) over the Indo-Gangetic basin this is also obvious from the higher water column.

Higher AOD is observed at lower wavelength $(440 \mathrm{~nm})$ showing strong atmospheric pollution with strong wavelength dependency of AOD at four wavelengths which confirm non-dusty days. Higher values of AOD could be due to background level of pollution in Beijing, whereas wavelength dependency of AOD is not seen during dusty days (9 March 2011). On 10 and 13 March 2013, AOD values are found to be low $(\sim 0.25)$ (Fig. $3 \mathrm{~b}$ ) with lower values of AQI 300 and $\mathrm{PM}_{2.5} \sim 300 \mu \mathrm{g} / \mathrm{m}^{3}$ show better air quality with respect to 09 March 2013 (Fig. 1b).

Figure 3c shows the Aerosol Volume Size Distribution (AVSD) on dusty days showing clearly bimodal mode which is not seen on the non-dusty days. The Coarse mode aerosols $(0.5-5) \mu \mathrm{m}$ show dominance over fine mode aerosols $(0.05-0.5) \mu \mathrm{m}$ on dusty days which indicates presence of mineral dust particles after dust storms over Beijing. For other days fine particles dominant due to smoke and biomass burning. The high concentration of coarse particles are clearly seen on 8 March 2013 just before dust storm, the bimodal nature of particle size is clearly seen on March 17 could be associated with dominance of anthropogenic aerosol particles which are the sources for dense cloud and fog. The aerosols volume size distribution is given in the Table 1, the AVSD maximum peak in coarse mode is around radius $2.39 \mu \mathrm{m}$ and in case of dusty days, the finer aerosol particles are less compared to coarser particles. A very similar variation in AVSD during dust events has also been reported over the IndoGangetic Basin (Dey et al. 2004).

In Fig. 4a-d vertical profiles of COVMR (CO volume mixing ratio) are shown in ascending (day time) and
Fig. 2 HYSPILT back trajectories show (combined with MODIS Terra image of 9 March and GOOGLE map) air mass reaching to south west region to Hubei region via Beijing on 9 March 2013, the dust originated from

Northwestern desert region of China and Mongolia

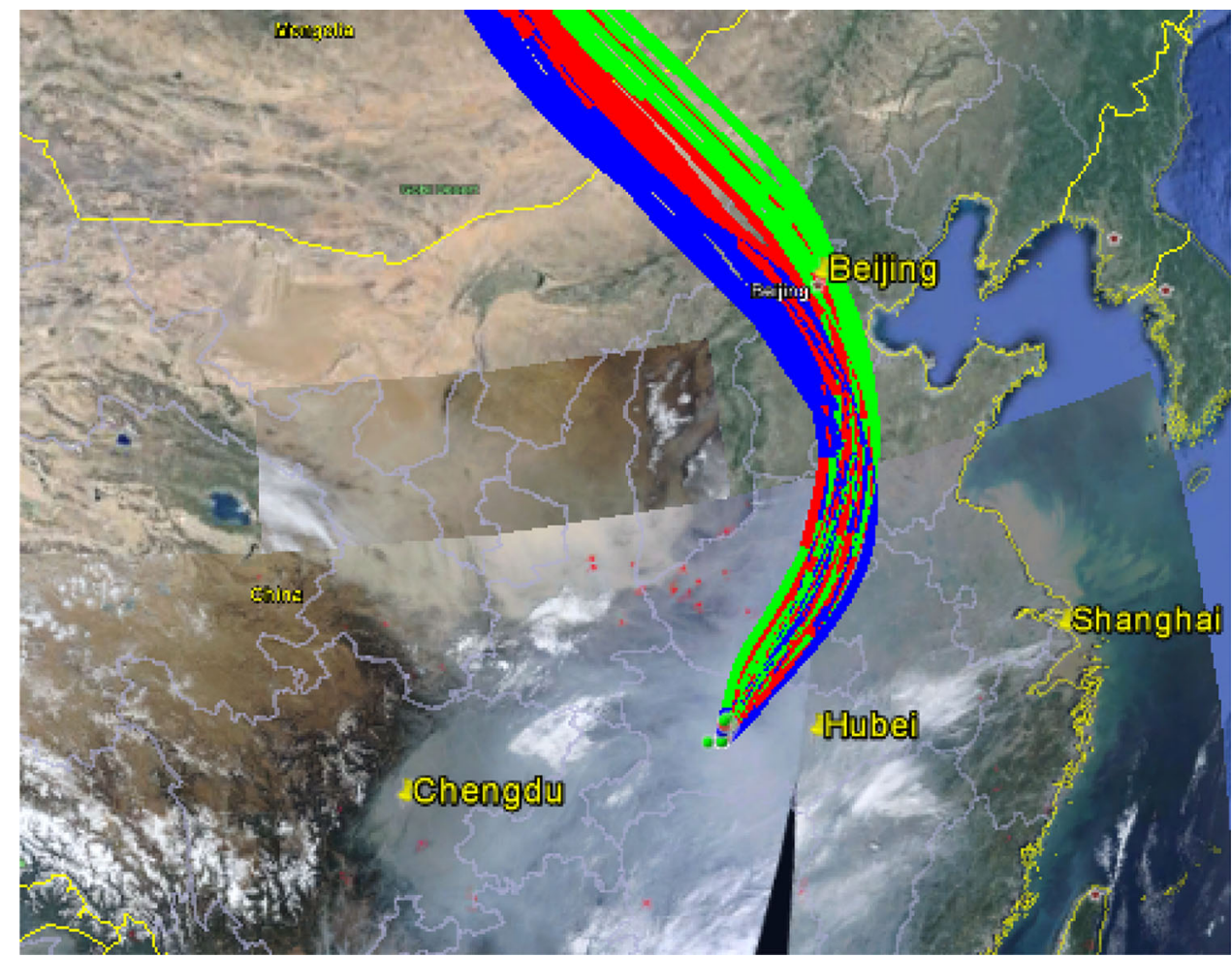


Fig. 3 a Daily variations of AOD, AE and water column (cm) (AERONET data),

b variations of AOD with four wavelengths $(\mathrm{nm})$ for different dusty and non-dusty days and c aerosol volume size distributions (AVSD)

(AERONET data) for the month of March 2013
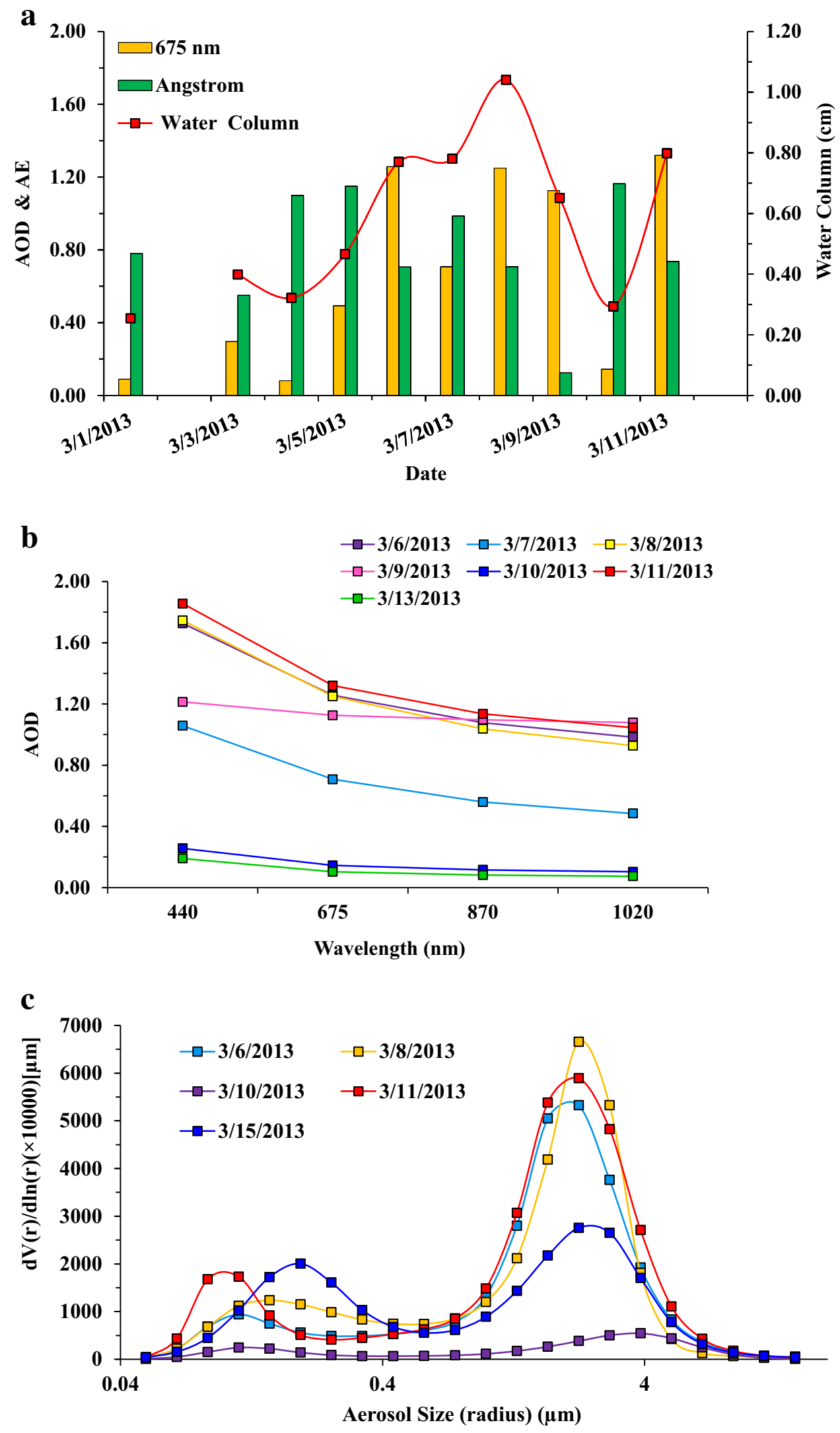
Table 1 shows distribution of size of particles on dusty and non-dusty days. On dusty days the volume is very high with higher size of dust particles

\begin{tabular}{cllcr}
\hline S. no. & Date & Radius $(\mu \mathrm{m})$ & Max_dV/dlnR $(\mu \mathrm{m}) \times 10,000$ & Avg_dV/dlnR $(\mu \mathrm{m}) \times 10,000$ \\
\hline Beijing & & & & \\
1 & $3 / 1 / 2013$ & 3.85 & 368.11 & 100.90 \\
2 & $3 / 3 / 2013$ & 2.93 & 1415.95 & 354.19 \\
3 & $3 / 4 / 2013$ & 5.06 & 288.96 & 93.32 \\
4 & $3 / 5 / 2013$ & 2.94 & 1117.57 & 454.11 \\
5 & $3 / 6 / 2013$ & 2.24 & 5325.85 & 1257.79 \\
6 & $3 / 8 / 2013$ & 2.39 & 6657.64 & 1392.99 \\
7 & $3 / 10 / 2013$ & 3.86 & 543.63 & 181.44 \\
8 & $3 / 11 / 2013$ & 2.24 & 5891.55 & 1516.44 \\
9 & $3 / 13 / 2013$ & 5.06 & 214.74 & 88.18 \\
10 & $3 / 14 / 2013$ & 2.94 & 1340.68 & 490.41 \\
11 & $3 / 15 / 2013$ & 2.24 & 2754.67 & 1037.75 \\
12 & $3 / 17 / 2013$ & 0.25 & 3067.66 & 1083.55 \\
\hline
\end{tabular}

a

Fig. 4 Variations of $\mathrm{CO}$ Volume Mixing Ratio (COVMR) at different pressure levels $(\mathrm{hPa})$ in (a) descending and (b) ascending modes; $\mathrm{CO}$ Volume Mixing Ratio (COVMR) at 905 and $681 \mathrm{hPa}$ levels in (c) descending and (d) ascending modes

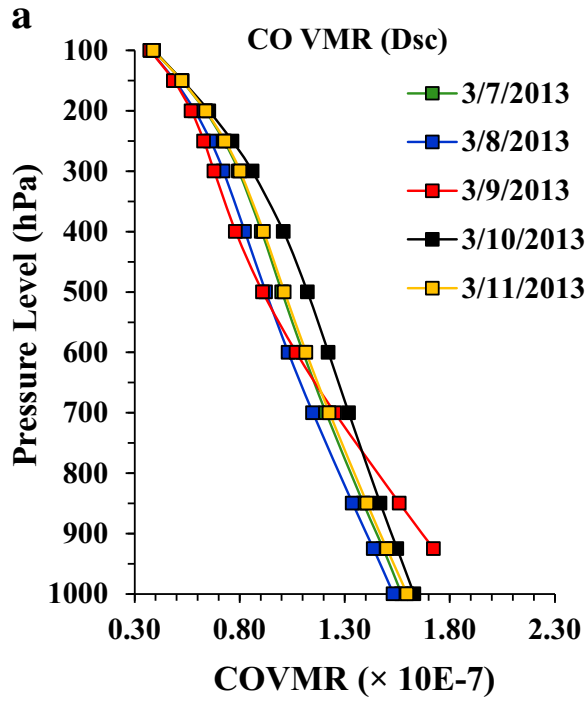

c

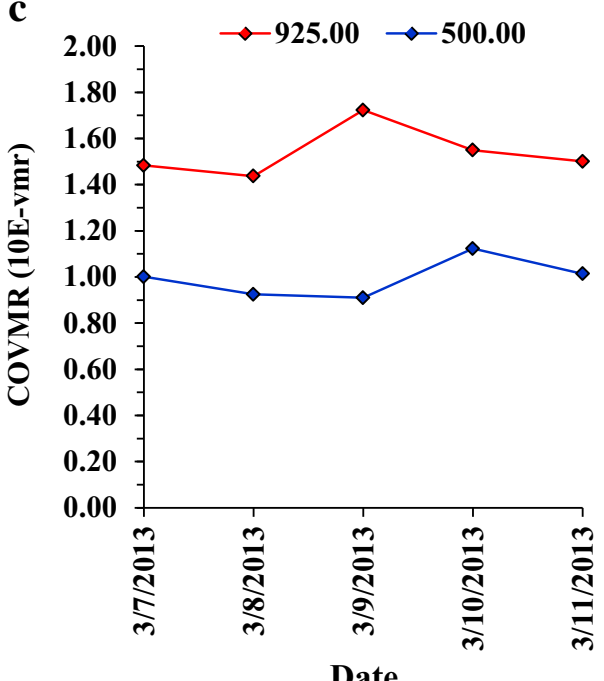

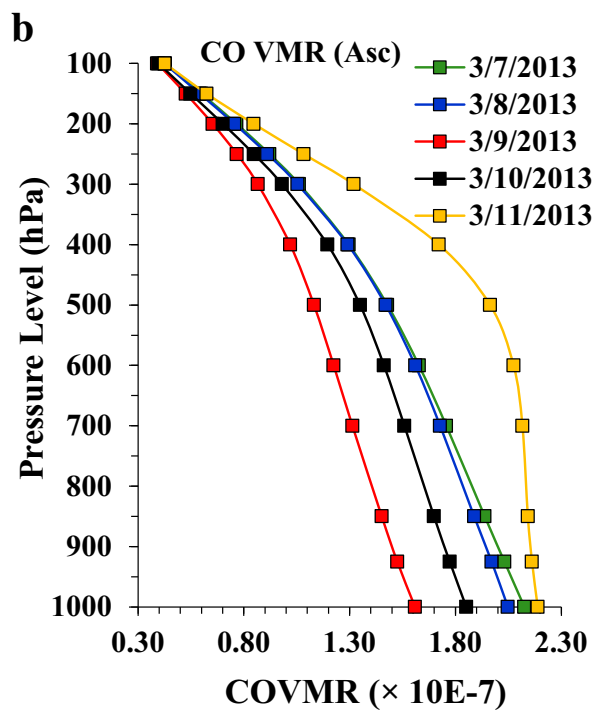

d

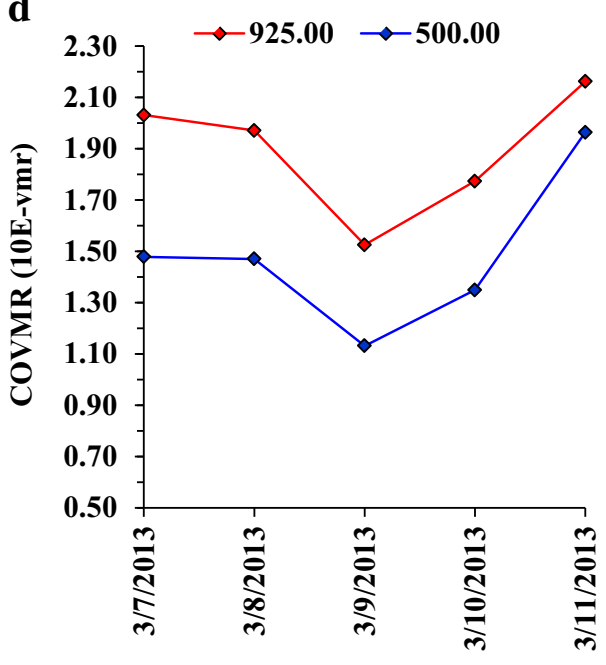

Date 
Fig. 5 Variations of $\mathrm{O}_{3}$ volume mixing ratio $\left(\mathrm{O}_{3} \mathrm{VMR}\right)$ at different pressure levels $(\mathrm{hPa})$ in (a) descending and

(b) ascending modes; (c) total ozone column (TOC in descending, TOC_Dsc and ascending, TOC_Asc mode) (DU) (AIRS Data) over Beijing
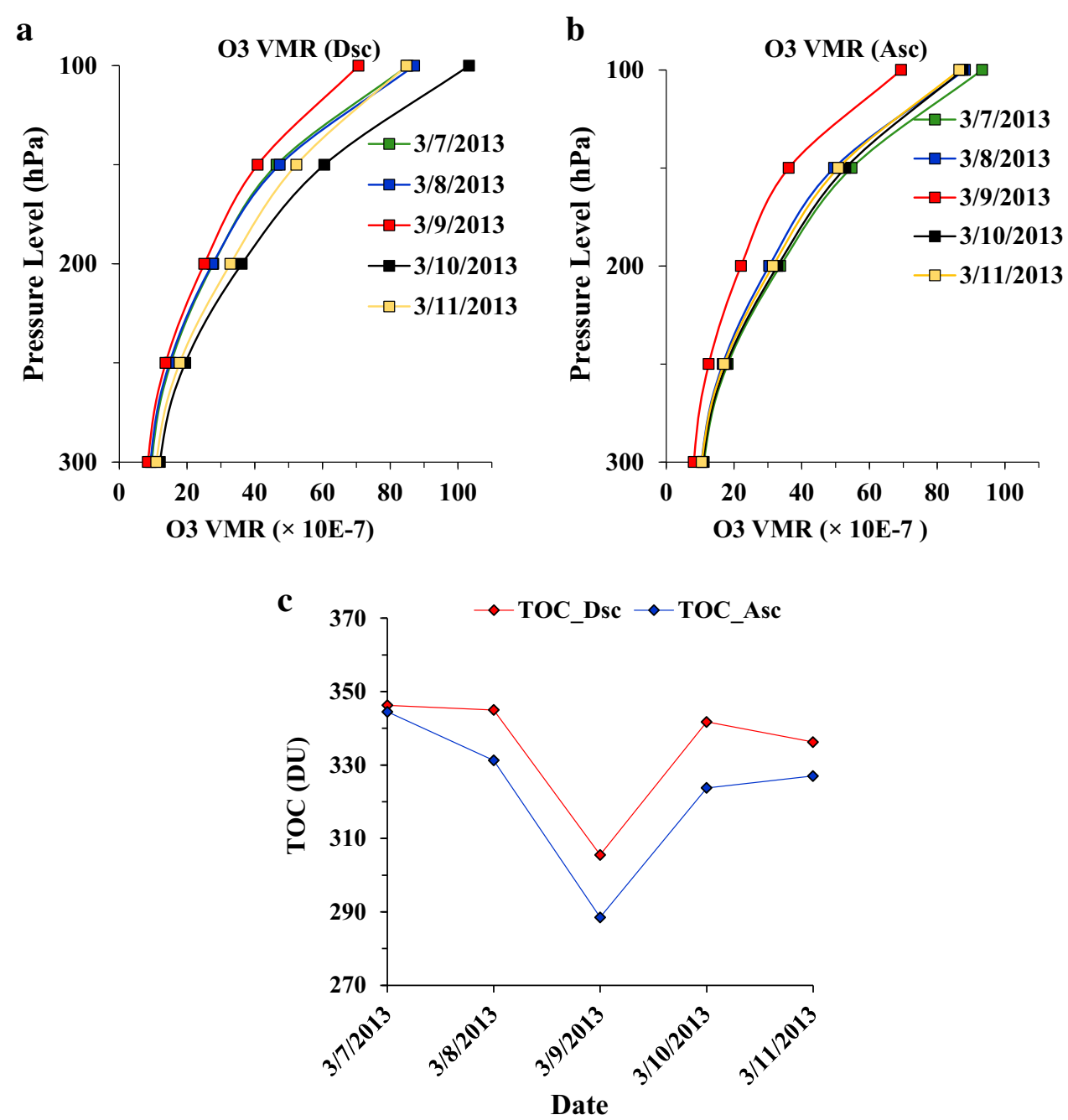

descending (night time) modes at different pressure levels and also at two pressure levels 905 and $618 \mathrm{hPa}$ for dusty and non-dusty days. The $\mathrm{CO}$ mixing ratio suggest the transport of anthropogenic emissions from the surroundings (rural and urban areas) with the dust along the track of dust. Changes in $\mathrm{CO}$ volume mixing are seen on the dusty days in both the modes. Enhancement in COVMR is found after the dust event on the ground, it seems that after dust event the $\mathrm{CO}$ volume mixing ratio enhanced on the ground. As dust storm started in evening of 08 March and lasts till 09 Morning so COVMR is less in descending mode on 08 March and also less in ascending mode on March 09, 2013 but enhancement is found in ascending and descending modes after 09 March day time. During night time (in descending mode), COVMR shows a big contrast in COVMR values at around $700-800 \mathrm{hPa}$ pressure levels. The enhancement of COVMR shows strong mixing of dust and anthropogenic emission. The COVMR ratio is found to be higher in descending mode compared to ascending mode meaning that the COVMR enhanced in the night at the higher pressure level after dust storm. Due to gap in the satellite coverage, few days gap in COVMR data is observed. The COVMR are not available at the same pressure levels due to technical specification of COVMR sensors.

In Fig. 5a,b and c vertical profiles of $\mathrm{O}_{3} \mathrm{VMR}\left(\mathrm{O}_{3}\right.$ Volume mixing ratio) are shown in ascending (day time) and descending (night time) modes at different pressure levels and the total ozone column (TOC) (AIRS Data) over Beijing with $1^{\circ} \times 1^{\circ}$. Changes in $\mathrm{O}_{3}$ volume mixing are seen on the dusty days in both the modes. Enhancement in $\mathrm{O}_{3}$ VMR is found after the dust event, it seems that dust event the $\mathrm{O}_{3}$ volume mixing ratio is reduced from ground to high altitudes. Changes in $\mathrm{O}_{3} \mathrm{VMR}$ are similar in COVMR as it is found to decrease during dust event and intensifies after 09 March. The average TOC during March 2013 is 362.48 and 360.25 Dobson Units (DU) ascending and descending modes, respectively. On 8 and 9 March, 2013, TOC is low compared to the average TOC value in both ascending (day time) and descending (night time) 
modes due to the dust storm. During same period, enhancement in UV to mid-visible Ångström exponent $(380-500 \mathrm{~nm})$ is observed supporting TOC observation, similar results are also observed during desert dust by Eck (1999) and O'Neill et al. (2001). After the dust storm, an enhancement in TOC is observed (Fig. 5c) which could be due to advection from the troposphere to stratosphere.

\section{Conclusion}

In this paper, we present detailed characteristics of aerosol and meteorological parameters associated with dust storm of 9 March 2013 in Beijing. The back trajectories clearly show the source of dust from desert in the northern parts of China and Mongolia. The satellite and ground data show pronounced changes in atmospheric and meteorological conditions associated with dust event, including AOD, Ångström exponent, fine particles, total ozone column (TOC) and AQI.

The characteristics of aerosol are very much dependent on the source region, track of the dust storms and the meteorological conditions along the track of dust storms. During the dust storm event of February and March 2013, $\mathrm{PM}_{2.5}$, AQI and AOD enhanced highly due to fog and haze at first, and decreased with the dust and strong wind. High AOD with low AE during dusty days were observed, indicating the presence of dust particles in the atmosphere. The optical properties of aerosol (ASD) also show changes during the dust storm event. The ASD on dusty days showing clearly bimodal mode which is not seen on the other days, and the finer aerosol particles are less compared to coarser aerosol particles on dusty days, representing the presence of large particles.

With regard to meteorological parameters, TOC during dusty days is lower compared to the average TOC in the month of March, an enhancement in COVMR shows strong mixing of dust and anthropogenic emissions. Such TOC and COVMR characteristics associated with dust storm over Beijing are similar to the observations made over the Indo-Gangetic plains (Prasad and Singh 2007a). In addition, higher values of $\mathrm{PM}_{2.5}$ and $\mathrm{AQI}$ during dusty days clearly show poor air quality that influences the human health. Such air quality values are alarming and efforts should be made to issue alerts to public not to expose during dusty days. The results presented here will be of great help to climate modeler to study short and long term climate effect since it is hard to get atmospheric and meteorological data at different pressure levels.

Acknowledgments The authors are grateful to NASA Giovanni team for providing data and also Hong-Bin Chen and Philippe Goloub, PIs of AERONET sites Beijing for maintaining AERONET site. The authors are also grateful to BMEMC for providing the AQI data.

\section{References}

Bhattacharjee PS et al (2007) Influence of a dust storm on carbon monoxide and water vapor over the Indo-Gangetic Plains. J Geophys Res 112:D18203. doi:10.1029/2007JD008469

Cao CX, Zheng S, Singh RP (2014) Characteristics of aerosol optical properties and meteorological parameters during three major dust events (2005-2010) over Beijing, China. Atmos Res 150:129-142

Chen Y et al (2009) Aircraft study of mountain chimney effect of Beijing, China. J Geophys Res 114:D08306. doi:10.1029/ 2008JD010610

Dey S et al (2004) Influence of dust storms on the aerosol optical properties over the Indo-Gangetic basin. J Geophys Res 109:D20211

Du WP et al (2008) Photometric measurements of spring aerosol optical properties in dust and non-dust periods in China. Atmos Environ 42:7981-7987

Dubovik O, King MD (2000) A flexible inversion algorithm for retrieval of aerosol optical properties from Sun and sky radiance measurements. J Geophys Res 105(D16):20673-20696. doi:10. 1029/2000JD900282

Dubovik O et al (2000) Accuracy assessments of aerosol optical properties retrieved from Aerosol Robotic federated instrument network and data archive for aerosol characterization. J Geophys Res 105(D8):9791-9806. doi:10.1029/2000JD900040

Eck TF (1999) Wavelength dependence of the optical depth of biomass burning, urban, and desert dust aerosols. J Geophys Res 104(D24):31333-31349

Gautam R, Hsu NC, Tsay SC et al (2011) Accumulation of aerosols over the Indo-Gangetic plains and southern slopes of the Himalayas: distribution, properties and radiative effects during the 2009 pre-monsoon season. Atmos Chem Phys $11: 12841-12863$

Gautam R, Hsu NC, Lau WK-M et al (2013) Satellite observations of desert dust-induced Himalayan snow darkening. Geophys Res Lett. doi:10.1002/grl.50226

Holben BN, Eck T, Slutser I et al (1998) AERONET a federated instrument network and data archive for aerosol characterization. Remote Sens Environ 66(1):1-16

Huang J, Minnis P, Yan H, Yi Y et al (2010) Dust aerosol effect on semi-arid climate over Northwest China detected from A-Train satellite measurements. Atmos Chem Phys 10:6863-6872

Kayetha VK, Senthilkumar J, Prasad AK et al (2007) Effect of dust storm on ocean color and snow parameters. J Indian Soc Remote Sens 35:1-9

Kumar S, Kumar S, Kaskaoutis DG, Singh RP, Singh RK, Mishra AK, Srivastava MK, Singh AK (2015) Meteorological, atmospheric and climatic perturbations during major dust storms over Indo-Gangetic Basin. Aeolian Res 17:15-31

Liu TS, Gu XF, An ZS et al (1981) The dust fall in Beijing, China on 18 April, 1980. Geol Soc Am Spec Pap 186:149-157

O'Neill NT, Eck TF, Holben BN, Smirnov A et al (2001) Bimodal size distribution influences on the variation of Angström derivatives in spectral and optical depth space. J Geophys Res 106:9787-9806

Painter TH, Bryant AC, Skiles SM (2012) Radiative forcing by light absorbing impurities in snow from MODIS surface reflectance data. Geophys Res Lett 39:L17502. doi:10.1029/2012GL052457

Prasad AK, Singh RP (2007a) Changes in aerosol parameters during major dust storm events (2001-2005) over the Indo-Gangetic 
Plains using AERONET and MODIS data. J Geophys Res 112:D09208. doi:10.1029/2006JD007778

Prasad AK, Singh RP (2007b) Changes in Himalayan snow and glacier cover between 1972 and 2000. EOS Trans AGU 88:326. doi:10.1029/2007EO330002

Prospero JM (1999) Long term measurements of the transport of African mineral dust to the south-eastern United States: implication for regional air quality. J Geophys Res 104:15917-15927

Qian WH, Quan LS, Shi SY (2002) Variations of the dust storm in China and its climatic control. J Clim 15:1216-1229

Singh RP (2014) Dust storms and their influence on atmospheric parameters over the Indo-Gangetic plains, pp 21-35, book chapter 2. In: Sundaresan J et al. (eds) Geospatial technologies and climate change, vol. 10. doi: 10.1007/978-3-319-01689-4_2

Singh RP, Prasad AK, Kayetha VK et al (2008) Enhancement of oceanic parameters associated with dust storms using satellite data. J Geophys Res 113:C11008. doi:10.1029/2008JC004815

Tong DQ, Dan M, Wang T et al (2012) Long term dust climatology in the western United States reconstructed from routine aerosol ground monitoring. Atmos Chem Phys 12:5189-5205. doi:10. 5194/acp-12-5189-2012

Uno I, Eguchi K, Yumimoto K, Liu Z et al (2011) Large Asian dust layers continuously reached North America in April 2010. Atmos Chem Phys 11:7333-7341
Wang XM, Dong ZB, Zhang JW et al (2004) Modern dust storms in China: an overview. J Arid Environ 58:559-574

Wang SG, Yuan W, Shang KZ (2006) The impacts of different kinds of dust events on $\mathrm{PM}_{10}$ pollution in northern China. Atmos Environ 40:7975-7982

Xin JY, Du WP, Wang YS, Xian GQ et al (2010) Aerosol optical properties affected by a strong dust storm over Central and Northern China. Adv Atmos Sci 27:562-574

Yu XN, Zhu B, Yin Y et al (2011) A comparative analysis of aerosol properties in dust and haze-fog days in a Chinese urban region. Atmos Res 99:241-247

Zhang RJ, Arimoto R, An JL et al (2005) Ground observations of a strong dust storm in Beijing in March 2002. J Geophys Res. doi:10.1029/2004JD004589

Zhang QJ, Laurent B, Velay-Lasry F et al (2012) An air quality forecasting system in Beijing-Application to the study of dust storm events in China in May 2008. J Envir Sci 24:102-111

Zhao C, Liu X, Leung LR (2012) Impact of the Desert dust on the summer monsoon system over Southwestern North America. Atmos Chem Phys 12:3717-3731. doi:10.5194/acp-12-3717-2012

Zheng S, Cao CX, Singh RP (2014) Comparison of ground based indices API and AQI) with satellite based aerosol products. Sci Total Environ 488:398-412 